\title{
Incomplete anaerobiosis as a cause of metronidazole 'resistance'
}

\author{
SHELAGH E. MILNE, E. JOAN STOKES, AND PAMELA M. WATERWORTH \\ From the Department of Microbiology, University College Hospital, London WC1E 6AU
}

SUMMARY Clostridium welchii, used as a control, was found to grow well in a microaerophilic jar used for campylobacters but appeared resistant to a metronidazole disc although the campylobacter was sensitive. Minimum inhibitory concentrations for six strains of $\mathrm{Cl}$. welchii were up to 64-fold higher in these conditions than when grown anaerobically. Zones of inhibition with both $\mathrm{Cl}$. welchii and Bacteroides fragilis varied with the amount of air admitted to anaerobic jars.

It was reported recently that metronidazole sensitivity discs can be inactivated by light (Jones and Scott, 1977); we report here another explanation for the apparent failure of these discs.

Some months ago, when testing the sensitivity of campylobacters to metronidazole, it was found that when Clostridium welchii was used as a control, this organism grew well in the microaerophilic conditions used but appeared resistant to metronidazole, although the campylobacter was sensitive. When retested anaerobically, the $\mathrm{Cl}$. welchii reverted to sensitive. This phenomenon is known to the manufacturers, who have demonstrated it with other clostridia, particularly $\mathrm{Cl}$. tertium.

Recently, an anaerobic sensitivity test was seen in the clinical laboratory in which the $\mathrm{Cl}$. welchii control showed little inhibition round the metronidazole discs, and it was suggested that the discs had deteriorated. The culture had been incubated in a BBL Gaspak jar, and regrettably the state of the indicator had not been noticed when the jar was opened, but as both discs were affected it seemed possible that the disc failure was due to incomplete anaerobiosis. This belief was strengthened when 10 discs taken from each of the bottles containing the original discs were tested and showed no loss of activity. Some experiments were then done to see how readily this phenomenon occurred.

\section{Material and methods}

Disc tests with campylobacter were done by the Stokes (1975) method on Columbia agar (Oxoid)

Received for publication 28 February 1978 with $5 \%$ horse blood added, both the test organism and the $\mathrm{Cl}$. welchii control being applied to the same plate with a $2.5 \mu \mathrm{g}$ metronidazole disc placed between them. These were incubated under microaerophilic conditions at $37^{\circ} \mathrm{C}$ overnight.

Minimum inhibitory concentrations were determined by the plate dilution method, using Oxoid blood agar base No. 2 with $5 \%$ lysed horse blood added. Plates were inoculated using a multiple replicator, with overnight cooked meat cultures diluted $1 / 100$. Cultures were incubated microaerophilically at $37^{\circ} \mathrm{C}$ overnight.

In the subsequent experiments, discs containing 2.5 and $10 \mu \mathrm{g}$ metronidazole (Mast Laboratories) were applied to plates of Isosensitest agar (Oxoid) flooded with cooked meat broth cultures diluted to give dense but not confluent growth.

The microaerophilic conditions used for the campylobacter experiments were produced by evacuating a McIntosh and Fildes jar without a catalyst by $60 \mathrm{~cm}$ mercury on the manometer, admitting approximately $10 \% \mathrm{CO}_{2}$ and replacing the remaining vacuum with $\mathrm{H}_{2}$.

Anaerobiosis was produced by evacuating McIntosh and Fildes jars containing catalysts by $60 \mathrm{~cm}$ mercury on the manometer and replacing this with a mixture of $\mathrm{N}_{2}(90 \%)$ and $\mathrm{H}_{2}(10 \%)$, the whole procedure then being repeated. BBL indicators were placed in all jars.

Controlled variations in the degree of 'anaerobiosis' were produced by admitting air measured in centimetres on the manometer after the second evacuation, before replacing the remaining vacuum with the $\mathrm{N}_{2} / \mathrm{H}_{2}$ mixture. When $\mathrm{CO}_{2}$ was also added, this was run in after the air and before the final $\mathrm{N}_{2} / \mathrm{H}_{2}$.

All jars were incubated overnight at $37^{\circ} \mathrm{C}$. 
Results

TESTS IN MICROAEROPHILIC CONDITIONS When $\mathrm{Cl}$. welchii was used as the control in tests with campylobacter using discs containing $2.5 \mu \mathrm{g}$ metronidazole, the former gave no zone of inhibition, whereas different strains of campylobacter gave zones measuring (from the edge of the disc to the edge of the zone) up to $8 \mathrm{~mm}$. When similar tests were incubated anaerobically the $\mathrm{Cl}$. welchii gave a zone of $8 \mathrm{~mm}$.

Minimum inhibitory concentrations of metronidazole were determined for six strains of $\mathrm{Cl}$. welchii. In the microaerophilic jar one strain failed to grow, three were inhibited by $16 \mu \mathrm{g} / \mathrm{ml}$, and two gave partial growth on this concentration, the highest tested. In the anaerobic jar four strains were inhibited by $0.25 \mu \mathrm{g} / \mathrm{ml}$ and one each by 0.5 and 1.0 $\mu \mathrm{g} / \mathrm{ml}$.

Seven strains of Bacteroides fragilis failed to grow in the microaerophilic jar. When these experiments were done, pure $\mathrm{H}_{2}$ was used in the jars, and despite there being no catalyst present, it was obvious from the vacuum found on opening the jar that some reduction had occurred. When $\mathrm{Cl}$. welchii was incubated in a campylobacter jar set up with the $\mathrm{N}_{2} / \mathrm{H}_{2}$ mixture now in use, only scattered colonies appeared, compared to a profuse growth on an anaerobic plate.

TESTS IN INCOMPLETELY ANAEROBIC

CONDITIONS

It was not found easy to produce precise variations in the oxygen content of the jars as this must depend on several variables. However, when no $\mathrm{CO}_{2}$ was added, reproducible results were obtained in a number of experiments. BBL indicators were completely reduced in jars to which $2.5,5$, or $7.5 \mathrm{~cm}$ air had been admitted; $C l$. welchii grew well, and there was no significant difference in the size of the zones of inhibition produced by discs containing 2.5 or $10 \mu \mathrm{g}$ metronidazole. When $10 \mathrm{~cm}$ air was admitted, there was usually at least a trace of blue on the indicator, and with $12.5 \mathrm{~cm}$ air the indicator was not reduced. $\mathrm{Cl}$. welchii grew well in both jars; in the former, both zones were substantially reduced, and in the latter that from the $10 \mu \mathrm{g}$ disc was further reduced and the $2.5 \mu \mathrm{g}$ disc showed no inhibition When $15 \mathrm{~cm}$ air was admitted growth was sparse, and the colonies varied greatly in size, but there appeared to be some inhibition round both discs, possibly the result of the reduced rate of growth of the organism. Some of these effects are illustrated (Figure).

Bact. fragilis was found to be much more sensitive to oxygen, but, by adding $\mathrm{CO}_{2}$ to the jars and admitting only small amounts of air, the same picture of diminished or obliterated zones of inhibition was obtained.

\section{Discussion}

With the interesting exception of some strains of campylobacter metronidazole is inactive against aerobic and microaerophilic organisms, but primary resistance is virtually unknown among obligate anaerobes. Indeed, resistance is frequently taken as

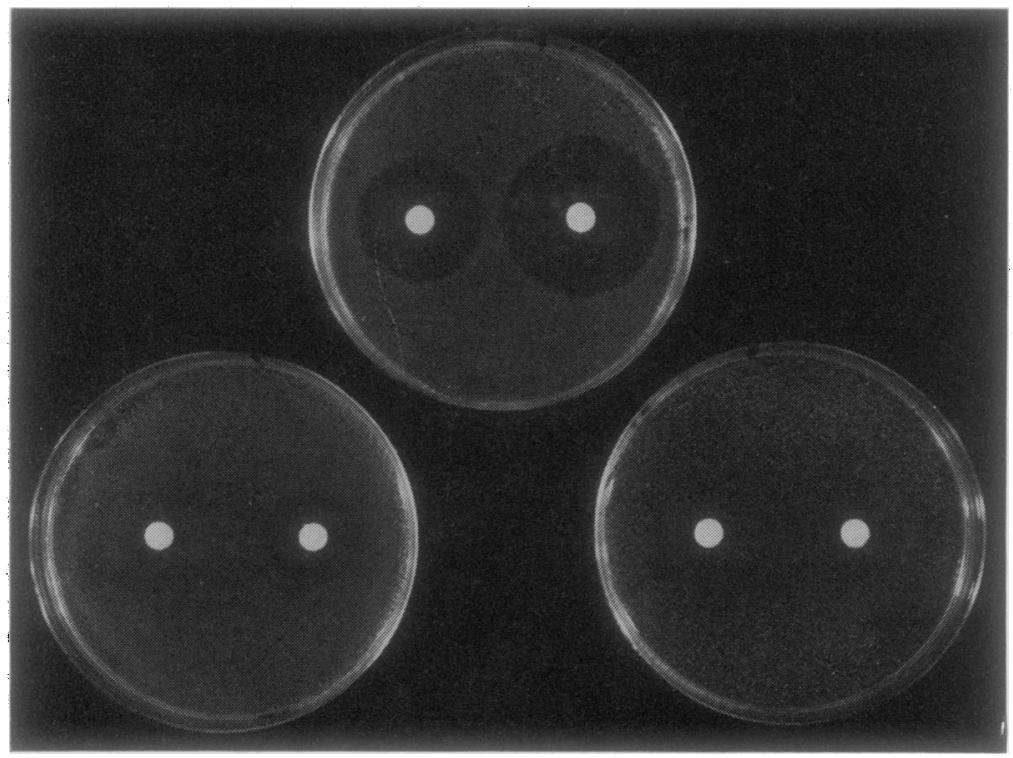

Fig. 1 Identical cultures of Cl. welchii incubated anaerobically (top) and in jars to which $10 \mathrm{~cm}$ (left) and $12.5 \mathrm{~cm}$ (right) of air had been admitted. Discs contain $2 \cdot 5 \mu \mathrm{g}$ and $10 \mu \mathrm{g}$ metronidazole. 
evidence that an organism is not an anaerobe. It now seems clear that unless the jar also contains a control organism showing full sensitivity to metronidazole, this argument is not valid. The incorporation of the control on the same plate as the test organism does not distinguish between incomplete anaerobiosis and an inactive disc, and it seems possible that, although these discs are certainly not above reproach, at least some may have been unfairly condemned; nevertheless, when the control zone is reduced, it does indicate the need to repeat the test.

In this department we prefer $\mathrm{Cl}$. welchii to Bact. fragilis as the control because the former is sensitive to penicillin and can therefore be used as the control for all the drugs tested. This organism now has the further advantage of readily revealing inadequate anaerobiosis; growth up to the disc is more convincing than failure of the control to grow, as might happen with Bact. fragilis.

This problem should also be borne in mind when testing metronidazole in microtitre trays, such as Sensititre (Seward), as these are not easy to render completely anaerobic, particularly if incubated in jars without valves.

One may speculate about the possible clinical significance of these findings. In most anaerobic infections the degree of anaerobiosis in vivo is probably high, but it seems unwise to rely entirely on metronidazole when hyperbaric oxygen is also being administered. In superficial lesions the amount of drug applied locally would probably outweigh reduced efficiency due to lack of anaerobiosis, but systemic treatment alone might be expected to fail.

\section{References}

Jones, P. H., and Scott, A. P. (1977). Light inactivation of metronidazole sensitivity discs. Journal of Clinical Pathology, 30, 1028-29.

Stokes, E. J. (1975). Clinical Bacteriology, 4th edition, p. 217. Arnold, London.

Requests for reprints to: Pamela M. Waterworth, Department of Microbiology, University College Hospital, Gower Street, London WC1E 6AU. 